\title{
Chromosomal diversification and karyotype evolution of diploids in the cytologically diverse genus Prospero (Hyacinthaceae)
}

Tae-Soo Jang ${ }^{1}$, Khatere Emadzade ${ }^{1}$, John Parker ${ }^{2}$, Eva M Temsch ${ }^{1}$, Andrew R Leitch ${ }^{3}$, Franz Speta ${ }^{4}$ and Hanna Weiss-Schneeweiss ${ }^{1 *}$

\begin{abstract}
Background: Prospero (Hyacinthaceae) provides a unique system to assess the impact of genome rearrangements on plant diversification and evolution. The genus exhibits remarkable chromosomal variation but very little morphological differentiation. Basic numbers of $x=4,5,6$ and 7, extensive polyploidy, and numerous polymorphic chromosome variants were described, but only three species are commonly recognized: $P$. obtusifolium, $P$. hanburyi, and $P$. autumnale s.l., the latter comprising four diploid cytotypes. The relationship between evolutionary patterns and chromosomal variation in diploids, the basic modules of the extensive cytological diversity, is presented.

Results: Evolutionary inferences were derived from fluorescence in situ hybridization (FISH) with $5 S$ and 355 rDNA, genome size estimations, and phylogenetic analyses of internal transcribed spacer (ITS) of 355 rDNA of 49 diploids in the three species and all cytotypes of $P$. autumnale s.l. All species and cytotypes possess a single 355 rDNA locus, interstitial except in $P$. hanburyi where it is sub-terminal, and one or two 5S rDNA loci (occasionally a third in P. obtusifolium) at fixed locations. The localization of the two rDNA types is unique for each species and cytotype. Phylogenetic data in the $P$. autumnale complex enable tracing of the evolution of rDNA loci, genome size, and direction of chromosomal fusions: mixed descending dysploidy of $x=7$ to $x=6$ and independently to $x=5$, rather than successive descending dysploidy, is proposed.

Conclusions: All diploid cytotypes are recovered as well-defined evolutionary lineages. The cytogenetic and phylogenetic approaches have provided excellent phylogenetic markers to infer the direction of chromosomal change in Prospero. Evolution in Prospero, especially in the P. autumnale complex, has been driven by differentiation of an ancestral karyotype largely unaccompanied by morphological change. These new results provide a framework for detailed analyses of various types of chromosomal rearrangements and karyotypic variation in polyploids.
\end{abstract}

Keywords: Chromosomal evolution, FISH, Genome size, Hyacinthaceae, ITS, Phylogeny, Prospero, rDNA

\section{Background}

Chromosomal change plays an important role in plant evolution, diversification, and speciation $[1,2]$. When carried out against a phylogenetic background $[1,3-5]$ comparative analyses of karyotypes allow inferences regarding evolutionary history.

Detailed physical chromosomal maps, which enable evolutionary patterns and processes to be determined,

\footnotetext{
* Correspondence: hanna.schneeweiss@univie.ac.at

${ }^{1}$ Department of Systematic and Evolutionary Botany, University of Vienna,

Rennweg 14, A-1030, Vienna, Austria

Full list of author information is available at the end of the article
}

can be constructed using FISH (fluorescence in situ hybridization) from both single copy and repetitive DNAs, such as rDNA, species- or genus-specific repetitive DNAs, individual chromosome DNAs [1,6-10]. Patterns of chromosomal evolution using FISH have been established in several economically important plant genera (e.g., Nicotiana [3,11], Beta [12]) as well as in model organisms and their wild relatives (e.g., Brassicaceae $[1,13])$. Comparative evolutionary cytogenetics of wild plant groups, however, has been much less explored (e.g., Hepatica [14], Anemone [15], Melampodium [16]).

\section{Biomed Central}

(c) 2013 Jang et al.; licensee BioMed Central Ltd. This is an Open Access article distributed under the terms of the Creative Commons Attribution License (http://creativecommons.org/licenses/by/2.0), which permits unrestricted use, distribution, and reproduction in any medium, provided the original work is properly cited. 
The markers of choice for cytogenetic evolutionary studies include tandemly repeated genes encoding $5 \mathrm{~S}$ and $35 \mathrm{~S}$ rRNA within the nucleus. The 35S rDNA loci (18S-5.8S-25S rDNA) are located in the nucleolarorganizer regions (NORs), while tandem arrays of $5 \mathrm{~S}$ rDNA map independently of them (but see [17]). Copy numbers of $5 \mathrm{~S}$ rDNA are usually lower than $35 \mathrm{~S}$ rDNA $[18,19]$. Since the coding regions of these two markers are conserved across large evolutionary units $[4,20]$ their localization provides useful landmarks for chromosome identification [20-22]. Partial DNA sequences of these two rDNA types (e.g., ITS of 35S rDNA or NTS of 5S rDNA) are also commonly used for inferring phylogenies $[16,23]$. This allows the interpretation of cytological information in a strict phylogenetic context, giving detailed insights into the patterns of evolution of genomes.

A particularly suitable system for analyzing the role of chromosomal change in plant diversification and speciation is provided by the genus Prospero Salisb. (Hyacinthaceae). This genus is distributed around the whole Mediterranean basin, north to Britain and Russia (Figure 1). Across this area Prospero exhibits exceptionally high levels of chromosomal variation, with basic chromosome numbers of $x=4,5,6$, and 7 , alongside levels of ploidy up to about 20-fold [24-26]. Three species are commonly recognized in the genus: $P$. obtusifolium (Poir.) Speta $(x=4)$ and P. hanburyi (Baker) Speta $(x=7)$, both chromosomally stable, and a dynamic species complex referred to as $P$. autumnale (L.) Speta. Within $P$. autumnale, up to 15 smaller, local, segregates have been described [27-33], but these are only subtly differentiated morphologically (quantitative differences and distinct chromosome numbers/ploidy levels, [32]). Thus, in this paper, we recognize only the three species as comprising Prospero for the clarity of the data interpretation. The relationship of genomic, chromosomal, and phylogenetic analyses to species delimitation and their correlation with distinct morphological characters will only emerge from broader evolutionary studies of the genus.

P. obtusifolium $(x=4)$ and P. hanburyi $(x=7)$ are morphologically distinct entities found within the range of the $P$. autumnale complex, the former two being geographically restricted to the western Mediterranean and to the Levant respectively. They are known only as diploids. By contrast, the $P$. autumnale complex exhibits a spectacular array of genomic and chromosomal variation, unparalleled in any other flowering plant, with multiple basic chromosome numbers, a huge range of levels and complexity of polyploidy, and a spectacular array of chromosomal polymorphisms (including supernumerary segments, B-chromosomes, and inversions). Four distinct diploid cytotypes with basic chromosome numbers of $x=5, x=6$, and two with $x=7$, have so far been described [24].

The two $x=7$ diploid cytotypes are referred to as AA and $B^{7} B^{7}$, with $A A$ found only in countries bordering the Atlantic Ocean in Iberia and North Africa and $B^{7} B^{7}$ occupying the countries around the Mediterranean Basin and on its islands; they overlap only in Spain [25]. The karyotype morphologies of $\mathrm{AA}$ and $\mathrm{B}^{7} \mathrm{~B}^{7}$ are very similar, but differ significantly in chromosome size and DNA amount, and, more trivially, in the location of the single NOR within chromosome $3[25,26,34]$. Cytotype $B^{7} B^{7}$

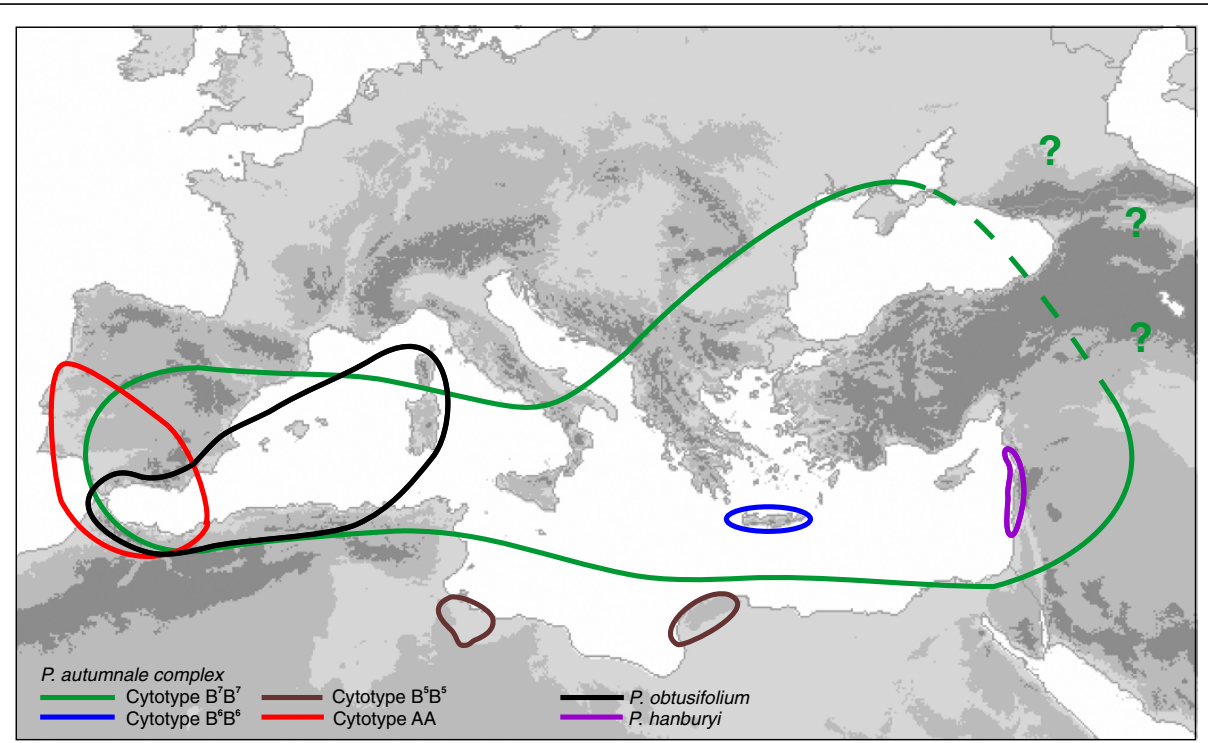

Figure 1 Map of distribution of diploid species and cytotypes of the genus Prospero. Dashed line in the eastern range of distribution of cytotype $B^{7} B^{7}$ and question marks indicate incomplete information on the distribution of this cytotype. 
has been hypothesized to be most similar to the ancestral karyotype of the complex [26].

Diploid plants based on $x=6$ (cytotype $\mathrm{B}^{6} \mathrm{~B}^{6}$ ) are endemic to Crete. The $\mathrm{B}^{6} \mathrm{~B}^{6}$ karyotype carries a large submetacentric chromosome referred to as $\mathrm{F}^{1}(6-7)[\mathrm{F}=$ fusion/fission; numbers in parentheses indicate chromosomes proposed to be involved in fusion/fission], while the remaining chromosomes correspond closely in morphology and homoeology to chromosomes $1-5$ of the $\mathrm{B}^{7} / \mathrm{A}$ genomes. A diploid of constitution $\mathrm{B}^{5} \mathrm{~B}^{5}$ is endemic to Libya [26] and carries two fission/fusion chromosomes, assigned to as $F^{2}(6-7)$ and $F^{3}(1-3)$, with respect to the karyotype of $\mathrm{A} / \mathrm{B}^{7}$ genome $[24,26]$.

Despite the enormous chromosomal and DNA amount variation within the $P$. autumnale complex, there is no large-scale accompanying morphological differentiation. The mechanisms involved in chromosome change and its directionality, might therefore allow us to infer evolutionary patterns within the genus. Within $P$. autumnale, we have previously $[24,35,36]$ attempted to establish phylogeny from chromosome numbers and karyotype structure supplemented by analyses of meiotic configurations in diploid hybrids. Two sequential chromosomal fusions were proposed for the reduction of the chromosome number from $x=7\left(\mathrm{AA}, \mathrm{B}^{7} \mathrm{~B}^{7}\right)$ to $x=6\left(\mathrm{~B}^{6} \mathrm{~B}^{6}\right)$ and $x=5\left(\mathrm{~B}^{5} \mathrm{~B}^{5}\right)$ [26]. In addition to this descending dysploid shift, genome size also varies, with a major discontinuity between genomes $B^{7}, B^{6}$ and $B^{5}$ and the large genome $A$ $[26,37]$. No evolutionary directionality has been ascribed to this change.

Phylogenetic relationships within the family Hyacinthaceae have been inferred from plastid DNA sequence analyses [38-40]. These studies, however, included only one or two accessions of Prospero (of unknown ploidy levels), so no assessment of phylogenetic relationships within the genus could be made. This present study provides the first comprehensive analysis of phylogenetic relationships among all the diploids identified in the genus Prospero, based on karyotype and genome size changes, analyzed against a rigorous DNA phylogeny, allowing previous hypotheses concerning karyotypic evolution to be tested. This study provides also a framework for studying evolutionary patterns in polyploid genomes of Prospero.

The aims of this study are to: (1) establish numbers and locations of $5 \mathrm{~S}$ and $35 \mathrm{~S}$ rDNA loci in all diploid species and cytotypes of Prospero; (2) analyze the evolution of rDNA loci and genome size in a phylogenetic context; (3) test previous hypotheses concerning the evolution of basic chromosome number in the P. autumnale complex; and (4) propose a new model for chromosomal rearrangements within the genus and to evaluate their role in the diversification of taxa.

\section{Results}

\section{Chromosome numbers and karyotype structure in the genus Prospero}

Chromosome counts confirmed all chromosome numbers reported earlier for diploids in the genus Prospero: $2 n=8,10,12$, and 14 (Table 1, Figure 2).

\section{Prospero obtusifolium}

All six plants of $P$. obtusifolium were diploid with $2 n=$ $2 x=8$ (Table 1, Figure 2). The karyotype consisted of three pairs of submetacentric and one pair of subtelocentric chromosomes (Figure 2) with Haploid Karyotype Length (HKL) of $29.01 \pm 0.77 \mu \mathrm{m}$ (Table 2). A single nucleolar-organizing region (NOR) was localized within the pericentric region of the short arm of chromosome 3 (Figure 2). The $1 C$ DNA amount of P. obtusifolium was $4.94 \pm 0.039 \mathrm{pg}$ (Table 2).

\section{Prospero hanburyi}

The three plants of $P$. hanburyi were diploid with $2 n=$ $2 x=14$ (Table 1, Figure 2), comprising four pairs of near-metacentric and three pairs of submetacentric chromosomes (Figure 2). The HKL was $44.90 \pm 4.04 \mu \mathrm{m}$ (Table 2). A single NOR was localized subterminally on the short arm of chromosome 2 (Figure 2). This contrasted to the interstitial localization of NORs in all other Prospero taxa and cytotypes. The $1 C$ content of $P$. hanburyi was $6.81 \pm 0.017 \mathrm{pg}$ (Table 2). The karyotypes of these two species showed little structural similarity to the diploid karyotypes within the $P$. autumnale complex (Figure 2).

\section{The Prospero autumnale complex}

The four diploid cytotypes (AA, $\mathrm{B}^{5} \mathrm{~B}^{5}, \mathrm{~B}^{6} \mathrm{~B}^{6}$, and $\mathrm{B}^{7} \mathrm{~B}^{7}$ ) of the $P$. autumnale complex differred not only in basic chromosome number, but also in karyotype structure due to fusion/fission and genome size (Table 1, Figure 2).

\section{Cytotype AA $(2 n=2 x=14)$}

In all six individuals the karyotype consisted of five submetacentrics (chromosomes 1-3 and 5-6), one subtelocentric (chromosome 4), and one near-metacentric (chromosome 7; Figure 2). The HKL was $48.35 \pm$ $7.15 \mu \mathrm{m}$ (Table 2) with a $1 C$ DNA content of $7.85 \pm$ $0.045 \mathrm{pg}$ (Table 2). A single NOR was adjacent to the centromere in the long arm of chromosome 3 (Figure 2).

\section{Cytotype $B^{7} B^{7}(2 n=2 x=14)$}

The karyotype in seventeen individuals consisted of five sub-metacentrics (chromosomes 1-3 and 5-6), one subtelocentric (chromosome 4), and one near-metacentric (chromosome 7), each identifiable by size and morphology (Table 1 and Figure 2). 
Table 1 Plant material studied with localities, chromosome numbers, and GenBank accession numbers of ITS DNA sequences

\begin{tabular}{llcc}
\hline Cytotype & Voucher information (accession number) & 2n & ITS GenBank accession number \\
\hline Outgroups & & & \\
Dipcadi sp. & cult. HBV (H336) & KC899267 \\
Othocallis siberica (Haw.) Speta & cult. HBV (H2159) & 12 & KC899268
\end{tabular}

Genus Prospero Salisb.

P. obtusifolium (Poir.) Speta

P. hanburyi (Baker) Speta

P. autumnale (L.) Speta s.l.

$\mathrm{AA}$

$B^{7} B^{7}$

$B^{6} B^{6}$
Spain, Parker s.n., cult. HBV (H540) 8

Morocco, Parker 15500-1, cult. HBV (H547)

Spain, Parker DL20, cult. HBV (H556)

Spain, Parker DL8, cult. HBV (H559)

Morocco, Parker 15607, cult. HBV (H563)

Morocco, Parker 15607, cult. HBV (H564)

Turkey, Findikpinar A, Leep s.n., cult. HBV (H115)

Turkey, Narlikuyu, Silifke, 475/01, cult. HBV (H231)

Turkey, Findikpinar, L75/T25, cult. HBV (H397)

Spain, Huelva, Parker s.n., cult. HBV (H541)

Spain, Badajoz, Parker CV3, cult. HBV (H543)

Spain, Huelva, Parker s.n., cult. HBV (H548)

Portugal, Peniche, Parker s.n., cult. HBV (H550)

Portugal, Peniche, Parker s.n., cult. HBV (H551)

Spain, Huelva, Parker s.n., cult. HBV (H557)

Greece, Crete, Speta KR245, cult. HBV (H47)

Greece, Peloponnisos, Speta 81, cult. HBV (H74)

Greece, Rhodos, Faliraki, Speta 52800, cult. HBV (H137)

Höner, s.n., cult. HBV (H228)

Cyprus, Speta 53872, cult. HBV (H239)

Greece, Samos, Tod 52684, cult. HBV (H241)

Montenegro, Speta s.n., cult. HBV (H422)

Montenegro, Speta s.n., cult. HBV (H424)

Italy, Sicily, Speta 51990, cult. HBV (H428)

Greece, Crete, Speta KR 15, cult. HBV (H440)

Speta 52746, cult. HBV (H447)

Greece, Kalamitsi, Speta 52690, cult. HBV (H450)

Greece, Crete, Speta s.n., cult. HBV (H460)

Greece, Naxos, Speta 3, cult. HBV (H575)

Serbia, Siget-Baun, Rat s.n., cult. HBV (H576)

Ukraine, Nikita, Roman RK4-1, cult. HBV (H591)

Israel, Nene Han, Parker, s.n., cult. HBV (H612)

Greece, Crete, Speta KR2O, cult. HBV (H158)

Greece, Crete, Speta CR95-99, cult. HBV (H166)

Greece, Crete, Speta 95-99, cult. HBV (H170)

Greece, Crete, Speta KR2O, cult. HBV (H195)

Greece, Crete, Jahn 854, cult. HBV (H197)
KC899275

KC899273

KC899276

KC899272

KC899277

KC899274

KC899269

KC899270

KC899271

KC899278

KC899279

KC899280

KC899281

KC899283

KC899282

KC899309

KC899308

KC899296

KC899295

KC899297

KC899310

KC899302

KC899305

KC899298

KC899306

KC899299

KC899311

KC899307

KC899300

KC899303

KC899304

KC899301

KC899289

KC899284

KC899285

KC899290

KC899286 
Table 1 Plant material studied with localities, chromosome numbers, and GenBank accession numbers of ITS DNA sequences (Continued)

\begin{tabular}{|c|c|c|c|}
\hline & Greece, Crete, Speta 52635, cult. HBV (H274) & 12 & KC899291 \\
\hline & Greece, Crete, N.B. 6890, cult. HBV (H340) & $12^{3}$ & KC899287 \\
\hline & Greece, Crete, Jahn 353, cult. HBV (H408) & 12 & KC899288 \\
\hline & Greece, Crete, Jahn \& Böhling 9131Z, cult. HBV (H427) & 12 & KC899293 \\
\hline & Greece, Crete, Speta CR95-99, cult. HBV (H468) & 12 & KC899292 \\
\hline & Greece, Crete, Speta 52613, cult. HBV (H520) & 12 & KC899294 \\
\hline \multirow[t]{6}{*}{$B^{5} B^{5}$} & Libya, Mt. Tobi, Parker s.n., cult. HBV (H566) & 10 & KC899313 \\
\hline & Libya, Mt. Tobi, Parker To-2, cult. HBV (H581) & 10 & KC899314 \\
\hline & Libya, Mt. Tobi, Parker To-28, cult. HBV (H582) & 10 & KC899316 \\
\hline & Libya, Mt. Tobi, Parker s.n., cult. HBV (H631) & 10 & KC899317 \\
\hline & Libya, Mt. Tobi, Parker s.n., cult. HBV (H637) & 10 & KC899312 \\
\hline & Libya, Nagasa, Parker s.n., cult. HBV (H640) & 10 & KC899315 \\
\hline
\end{tabular}

${ }^{1}$ One locus of 5 S rDNA.

${ }^{2}$ Duplication of $5 \mathrm{~S}$ rDNA locus in chromosome 1.

${ }^{3}$ Translocation of NOR of one on the homologous chromosomes 3 to chromosome $F^{1}(6-7)$.

${ }^{4}$ Translocation of both NORs to chromosome $F^{1}(6-7)$.

Plant material is in cultivation in Botanical Garden of the University of Vienna (HBV). Each individual in cultivation has a unique ID (in brackets, e.g., H336).

The karyotypes of $\mathrm{A}$ and $\mathrm{B}^{7}$ genomes were extremely similar in morphology and the numbers indicated homoeologies. HKL and $1 C$ DNA contents have been established in selected individuals, which differed in their $5 \mathrm{~S}$ rDNA locus number (for details see below). The HKLs were $28.70 \pm 1.74 \mu \mathrm{m}$ and $33.76 \pm 1.45 \mu \mathrm{m}$ while genome sizes were $4.45 \pm 0.023 \mathrm{pg}$ and $4.23 \pm 0.048 \mathrm{pg}$ respectively (Table 2 ). A single NOR was adjacent to the centromere in the long arm of chromosome 3 (Figure 2). Cytotype $\mathrm{B}^{7} \mathrm{~B}^{7}$ is the most widespread in P. autumnale.

\section{Cytotype $B^{6} B^{6}(2 n=2 x=12)$}

In all eleven bulbs, the karyotype consisted of four sub-metacentrics (chromosomes 1-3 and 5), one subtelocentric (chromosome 4), and one large submetacentric presumptive fusion chromosome classified as chromosome number $\mathrm{F}^{1}(6-7)$. Chromosome numbering again reflects homoeology to $\mathrm{B}^{7}$ and $\mathrm{A}$ genomes (Figures 2 and 3, Additional file 1: Figure S1).

In nine individuals, both NORs were located in the long arm of the chromosome homoeologous to chromosome 3, although in a more median position (Figure 2). The other two individuals (from different populations) have apparently undergone translocation of one or both NOR regions, respectively. In one, the NORs were located in both homologues of chromosomes 6 (accession H197; Figure 2), and in the other in chromosome 3 and the same position on chromosome 6 (accession H340; Figure 2). The HKL of standard individuals was $38.34 \pm$ $1.24 \mu \mathrm{m}$ with a $1 C$ DNA content of $6.27 \pm 0.083 \mathrm{pg}$ (H274; Table 2). The HKL of the NOR translocation heterozygote $\mathrm{H} 340$ was slightly lower and the genome size slightly smaller $(30.03 \pm 1.99 \mu \mathrm{m}$ and $6.07 \pm 0.031 \mathrm{pg}$; Table 2) while NOR translocation homozygote H197 had HKL of $34.97 \pm 3.98 \mu \mathrm{m}$ and genome size of $6.05 \pm$ $0.011 \mathrm{pg}$ (Table 2).

\section{Cytotype $B^{5} B^{5}(2 n=2 x=10)$}

In the six $\mathrm{B}^{5} \mathrm{~B}^{5}$ individuals, the karyotype comprised two sub-metacentrics (chromosomes 2 and 5), one subtelocentric (chromosome 4) (again reflecting homoeologies with $\mathrm{B}^{7}$ and $\mathrm{A}$ genomes), a large sub-metacentric fission/ fusion chromosome $\mathrm{F}^{2}(6-7)$, and a sub-metacentric fission/fusion chromosome $\mathrm{F}^{3}(1-3)$ (Figure 2). In $\mathrm{B}^{5} \mathrm{~B}^{5}$, the HKL was $29.67 \pm 2.58 \mu \mathrm{m}$ and the $1 C$ DNA amount $4.86 \pm 0.002 \mathrm{pg}$ (Table 2). It has been proposed previously that $B^{5} B^{5}$ results from two fusions, one identical to that in the $\mathrm{B}^{6} \mathrm{~B}^{6}$ karyotype $\left(\mathrm{F}^{1}=\mathrm{F}^{2}\right)$. The second fusion $\left(\mathrm{F}^{3}\right)$ was more complex, but has been interpreted to be a result of chromosome 1 and 3 fusion (Additional file 1: Figure S1) relocating the NOR to the short arm of an enlarged fusion chromosome $\mathrm{F}^{3}$ (Additional file 1: Figure S1).

\section{$5 \mathrm{~S}$ and $35 \mathrm{~S}$ rDNA localisation}

The three species of Prospero and all cytotypes invariably had one 35S rDNA locus per genome (Figure 2, Additional file 2: Figure S2). Its chromosomal localization was predominantly interstitial and adjacent to the centromere, except in P. hanburyi where it was sub-terminal. Either one or two 5S rDNA loci were found with a third, minor, locus in P. obtusifolium (Figure 2, Additional file 2: Figure S2). Locations of these loci were more variable than the $35 \mathrm{~S}$ rDNA loci. 


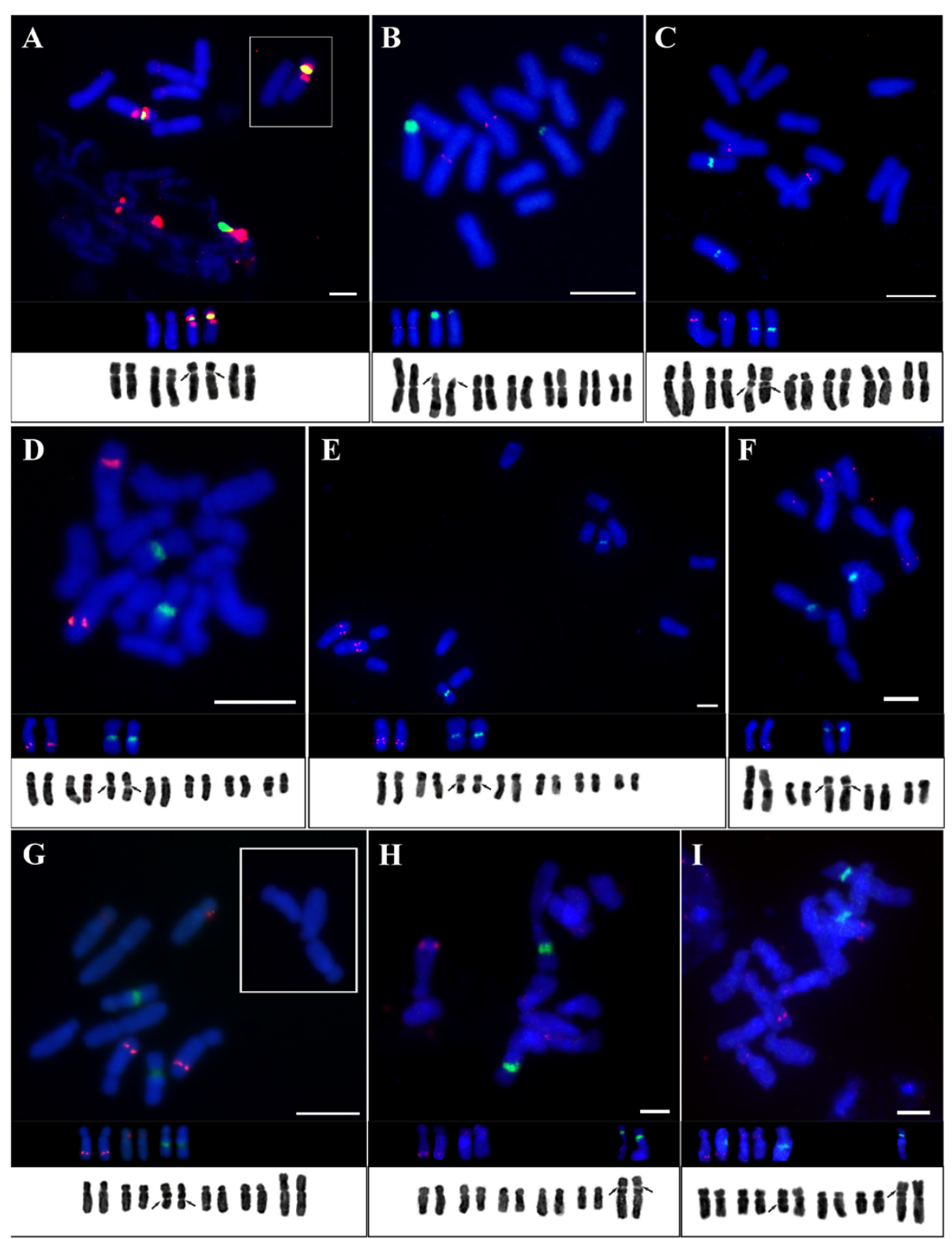

Figure 2 Karyotypes and localization of $35 \mathrm{~S}$ (green) and 5S (red) rDNA loci in diploids of Prospero. (A) P. obtusifolium; (B) P. hanburyi; (C-I) P. autumnale complex: (C) AA; (D) $B^{7} B^{7} ;$ (E) $B^{7} B^{7}$ with duplicated $5 S$ rDNA locus in chromosome 1 ; (F) $B^{5} B^{5} ;(\mathbf{G}) B^{6} B^{6} ;(\mathbf{H}) B^{6} B^{6}$ with homozygous NOR translocation (NOR in pair of chromosome 6); (I) $B^{6} B^{6}$ with heterozygous NOR translocation (NOR in one of each chromosome 3 and 6). Insets in (A) and (G) show chromosomes of a single cell which were lying at some distance from the main chromosome group and either could not be photographed together using high magnification objectives or were too far apart to clearly demonstrate chromosome morphology while showing the whole field. Scale bar $=5 \mu \mathrm{m}$.

i. The $35 \mathrm{~S}$ rDNA locus of $P$. hanburyi was subterminal on the short arm of chromosome 2, whereas the single $5 \mathrm{~S}$ rDNA locus was located on the long arm of metacentric chromosome 1 adjacent to the centromere (Figure 2B).

ii. In P. obtusifolium, the $35 \mathrm{~S}$ rDNA locus was on chromosome 3 , flanked on each side by a $5 \mathrm{~S}$ rDNA locus (Figure 2A). An additional minor $5 \mathrm{~S}$ rDNA locus was seen occasionally, located on the long arm of chromosome 2 (Figure 2A).

iii. All cytotypes of $P$. autumnale possessed a single interstitial 35S rDNA locus, usually closely adjacent to a centromere. There were either one or two $5 \mathrm{~S}$ rDNA loci in different cytotypes (Figure 2):

- in the AA cytotype, a single 5S rDNA locus was found in the pericentric region of the short arm 
Table 2 Genome size, karyotype length and rDNA loci number and localization in Prospero

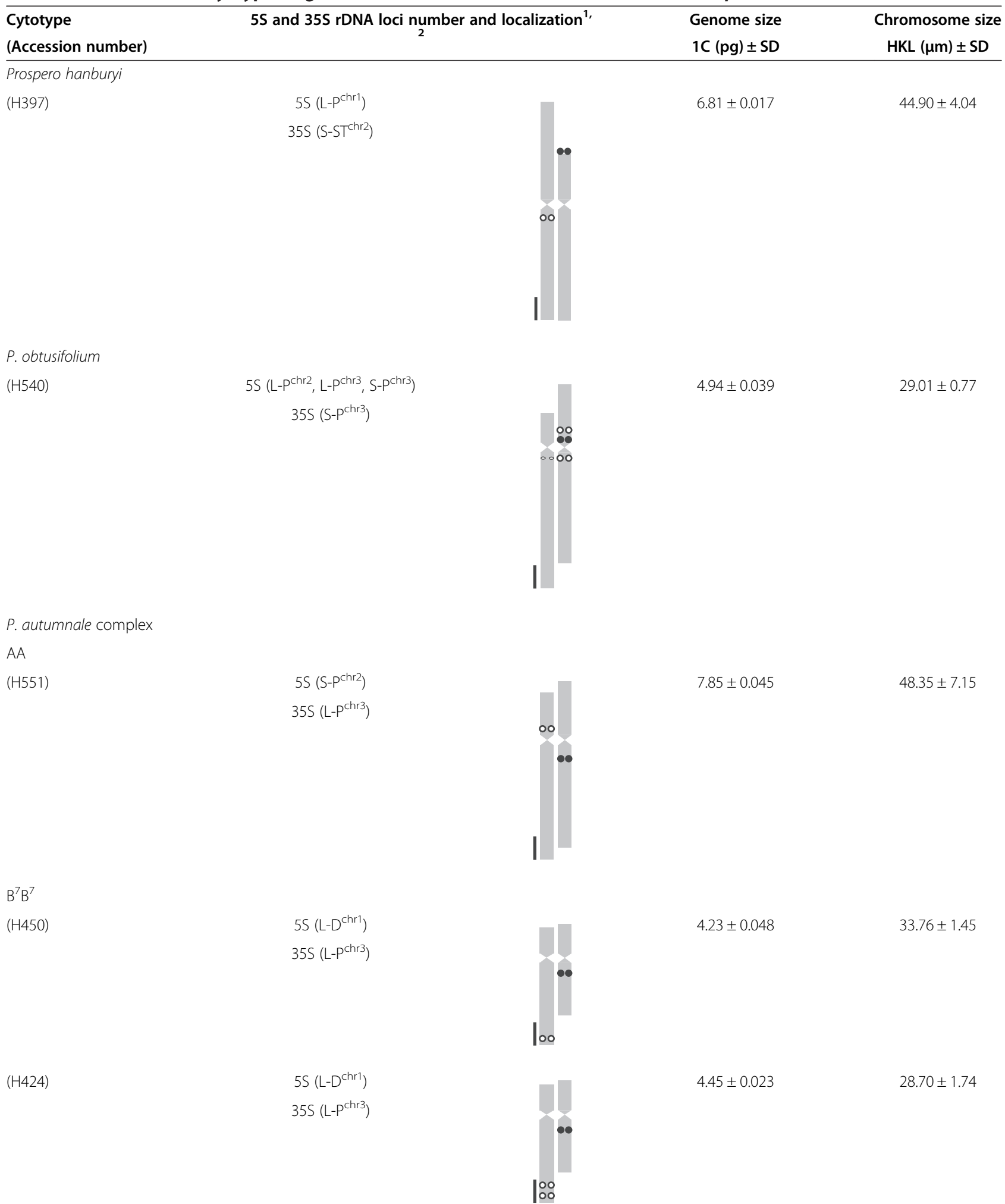


Table 2 Genome size, karyotype length and rDNA loci number and localization in Prospero (Continued)

$\mathrm{B}^{6} \mathrm{~B}^{6}$

$(\mathrm{H} 274)$

(1)

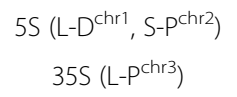

(H640)

$$
355(5-2+13)
$$

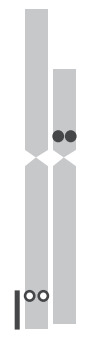

Translocations

$B^{6} B^{6}$

(H197)
$5 S$ (L-D ${ }^{\text {chr1 }}$, S-P ${ }^{\text {chr2 }}$ )
$35 \mathrm{~S}$ (S-P ${ }^{\mathrm{chr}}$ )

$6.27 \pm 0.083$

$38.34 \pm 1.24$ $\infty 0$

100

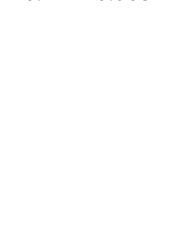

$4.86 \pm 0.002$

$29.67 \pm 2.58$

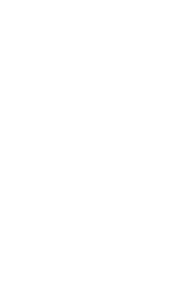

$6.05 \pm 0.011$

$34.97 \pm 3.98$

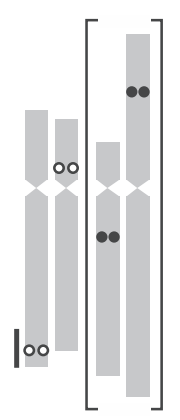

$6.07 \pm 0.031$

$30.03 \pm 1.99$

\section{$\infty$}

100
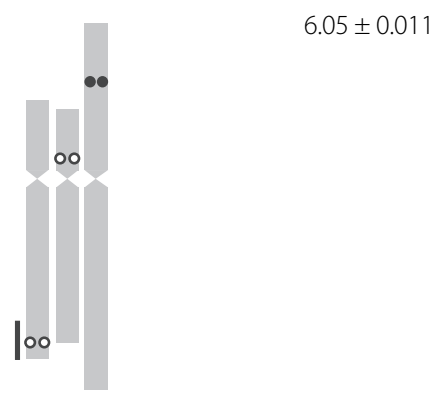

(2.03 1.99
$B^{6} B^{6}$

$(\mathrm{H} 340)^{3}$
$5 S$ (L-D chr1, S-P $\left.{ }^{\text {chr2 }}\right)$

$35 S$ (L-Pchr3, S-Pchr6)

\footnotetext{
$\overline{1}$ L, long arm; S, short arm; D, distal (interstitial) location of $5 \mathrm{~S}$ rDNA; P, pericentric location of $5 \mathrm{~S}$ or $35 \mathrm{~S}$ rDNA; ST, subterminal location of $35 \mathrm{~S}$ rDNA; chr , number of the chromosome.

${ }^{2}$ Scale bar $=1 \mu \mathrm{m}$; only the chromosomes bearing rDNA are shown: filled and open circles indicate position of 35S and 5S rDNA loci, respectively.

${ }^{3}$ Heterozygote; both chromosomes carrying 35S rDNA (chromosome 3 and chromosome 6) are shown.
}

of chromosome 2 (Figure 2C). The 35S rDNA locus was close to the centromere in the long arm of chromosome 3;

- cytotype $B^{7} B^{7}$ usually had a single $5 S$ rDNA locus localized interstitially within distal region of the long arm of chromosome 1. Some individuals, however, had two loci in close proximity at this position, suggesting either local duplication of this chromosomal region or of the locus itself (Figure 2D-E). The single 35S rDNA locus was 


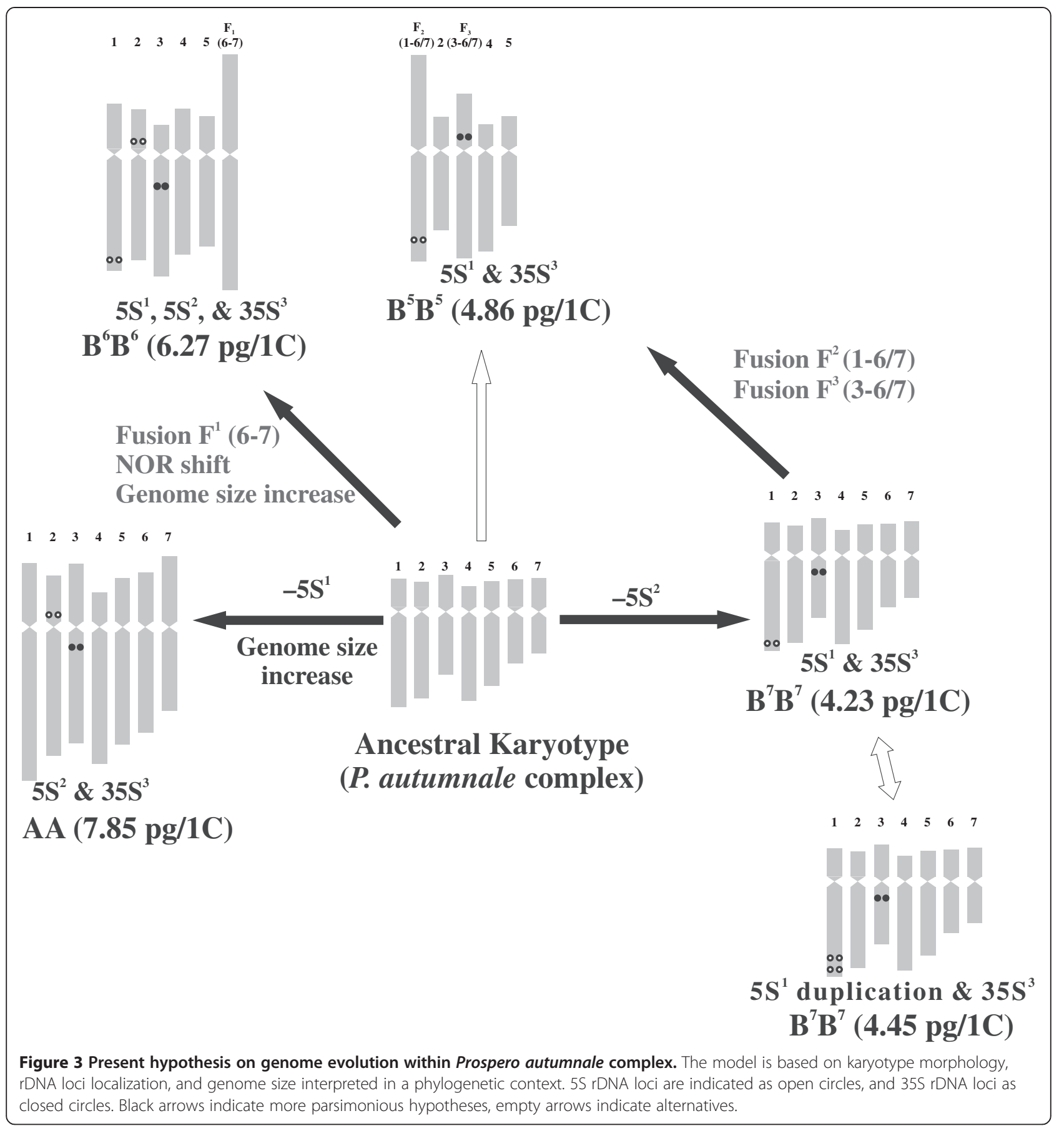

pericentromeric on chromosome 3 long arm (Figure 2D-E), in a similar location to that in AA (Figure 2C);

- cytotype $\mathrm{B}^{6} \mathrm{~B}^{6}$ always had two $5 \mathrm{~S}$ rDNA loci, a smaller one in the pericentric region of the short arm of chromosome 2 as in cytotype AA (Figure $2 \mathrm{G}$ ) and a larger one in the distal region of the long arm of chromosome 1 as in $\mathrm{B}^{7} \mathrm{~B}^{7}$. In most plants, there was a single $35 \mathrm{~S}$ rDNA locus interstitial in the long arm of chromosome 3, although further from the centromere than that in $A A$ and $B^{7} B^{7}$ (Figure $2 C-E$ ). Two plants differed from the standard pattern in their rDNA localization. In one individual, the $35 \mathrm{~S}$ rDNA locus was close to the centromere in the short arm of submetacentric chromosome 6 (Figure $2 \mathrm{H}$ ). In the 
other, one copy of the locus was detected in chromosome 6 and the other in the typical position on chromosomes 3 (Figure 2I).

- In the $\mathrm{B}^{5} \mathrm{~B}^{5}$ cytotype, putative fusion chromosome $\mathrm{F}^{2}(6-7)$ (Additional file 1: Figure S1) [26] had a 5S rDNA locus distal in one arm (Figure 2F). The 35S rDNA locus was localized interstitially close to the centromere within the short arm of the secondlargest chromosome in the complement (Figure 2F), the putative fusion chromosome $\mathrm{F}^{3}(1-3)$ (Additional file 1: Figure S1) [26].

\section{Phylogenetic relationships within Prospero based on ITS sequence data}

Sequence analyses of ITS1 and ITS2 regions, including the intervening $5.8 \mathrm{~S}$ coding region, of $35 \mathrm{~S}$ rRNA have provided insights into the relationships amongst the diploids of Prospero (Figure 4). The length of the ITS region of the 49 analyzed diploid Prospero accessions ranged from 778 to $785 \mathrm{bp}$ and the final, aligned dataset was $793 \mathrm{bp}$ long. The maximum parsimony analysis of the ITS dataset resulted in four most parsimonious trees with a length of 216 steps (65 parsimony informative characters, consistency index $[\mathrm{CI}]=0.926$, retention index $[\mathrm{RI}]=0.965$, rescaled consistency index $[\mathrm{RC}]$ $=0.893$ ). The final tree was rooted with two outgroup taxa (Othocallis siberica and Dipcadi sp., both in family Hyacinthaceae; Table 1). The genus Prospero was monophyletic (BS 99; Figure 4B). P. obtusifolium (6 individuals) and $P$. hanburyi ( 3 individuals) each formed well-supported clade (bootstrap support, BS 100). $P$. obtusifolium and P. hanburyi ITS regions differed by 29 substitutions, one of which is within one of two insertions ( 3 and 4 bp long) shared only by these two taxa (Additional file 3: Figure S3). P. hanburyi had an additional unique insertion of $3 \mathrm{bp}$. $P$. hanburyi and $P$. obtusifolium differed from $\mathrm{B}^{7} \mathrm{~B}^{7}$ diploids by the above mentioned two shared insertions and by 13 and 28 substitutions, respectively (Additional file 3: Figure S3). P. obtusifolium (BS 100) was recovered as sister to clade comprising $P$. hanburyi and P. autumnale (BS 81). The $P$. autumnale complex formed a monophyletic and well-supported clade (BS 90). Within this clade cytotype AA (six individuals), formed a monophyletic sub-clade (BS 100; Figure 4). ITS sequences of all AA individuals were identical. ITS region of cytotype AA has two unique insertions ( 1 and 2 bp long, respectively; Additional file 3: Figure S3). The $\mathrm{B}^{7} \mathrm{~B}^{7}$ cytotype (17 individuals) forms a well-supported clade (BS 98; Figure 4). This was the only cytotype within which ITS sequence variation has been observed (four distinct $B^{7} B^{7}$ groups, each having a unique substitution; Additional file 3: Figure S3). Interestingly, $B^{7} B^{7}$ clade includes all six individuals of the $\mathrm{B}^{5} \mathrm{~B}^{5}$ cytotype nested within it (Figure 4A), or forming a sub-clade of unresolved relationship to $\mathrm{B}^{7} \mathrm{~B}^{7}$ subclade with a bootstrap support of 86 (Figure $4 B$ ). All $B^{5} B^{5}$ individuals shared a unique 2 bp insertion compared with the $B^{7}$ ITS sequence.

The $\mathrm{B}^{6} \mathrm{~B}^{6}$ cytotype $(2 n=2 x=12$; eleven individuals $)$ formed a well-supported monophyletic group (BS 100; Figure 4). The two $\mathrm{B}^{6} \mathrm{~B}^{6}$ individuals with the $35 \mathrm{~S}$ rDNA translocation did not show any ITS variation compared to other analyzed individuals. The ITS sequences of genomes $\mathrm{B}^{6}$ shared four unique substitutions (Additional file 3: Figure S3).

\section{Discussion}

\section{Chromosome numbers and karyotype variation}

The genus Prospero is highly variable in chromosome number and chromosome structure. Basic numbers have changed by dysploidy $(x=4,5,6$, and 7) and, superimposed on this, high levels of auto- and allopolyploidy have evolved $[24,26]$. Three species are commonly recognized in the genus: P. obtusifolium, confined to the western Mediterranean islands and adjacent mainland, exclusively diploid with $2 n=8 ; P$. hanburyi from the Levant, also a diploid but with $2 n=14$; and the widespread $P$. autumnale complex with basic numbers of $x=5,6$, and 7 and an elaborate, reticulating autoand allopolyploid series (from $3 x$ to about $20 x$, but most frequently $4 x$ and $6 x ;[24-26,28,29,34,37,41])$.

Within the $P$. autumnale complex, four distinct cytotypes have been described and characterized so far $[24,26]$. A fifth genome, designated as $B^{7 *}$ (or C), with chromosomes slightly smaller than $B^{7}$ but of the same complement morphology, has so far been found only in allopolyploids on Crete [26]. The diploid cytotypes differ in chromosome number $\left(2 n=2 x=10\left[\mathrm{~B}^{5} \mathrm{~B}^{5}\right], 12\left[\mathrm{~B}^{6} \mathrm{~B}^{6}\right]\right.$, 14. $\left.\left[\mathrm{AA}, \mathrm{B}^{7} \mathrm{~B}^{7}\right]\right)$, in karyotype structure with one and two putative fusions resulting in $\mathrm{B}^{6}\left(\mathrm{~F}^{1}\right)$ and $\mathrm{B}^{5}\left(\mathrm{~F}^{2}\right.$ and $\left.\mathrm{F}^{3}\right)$ respectively, in NOR position, and in genome size, with a major difference in DNA amount between the A genome and the other three [26,37]. These studies are supported here, except that a few individuals with translocations were detected.

A combination of karyotypic features (chromosome size, morphology, NOR position, unique and stable locations of $5 \mathrm{~S}$ and $35 \mathrm{~S}$ rDNA loci, genome size) allows unambiguous identification of each cytotype as well as identification of homoeologous chromosomes between them (Figure 3). The karyotypes of $P$. hanburyi and P. obtusifolium differ from those of the P. autumnale complex to such an extent that it is impossible to infer any homoeologies between these taxa. 


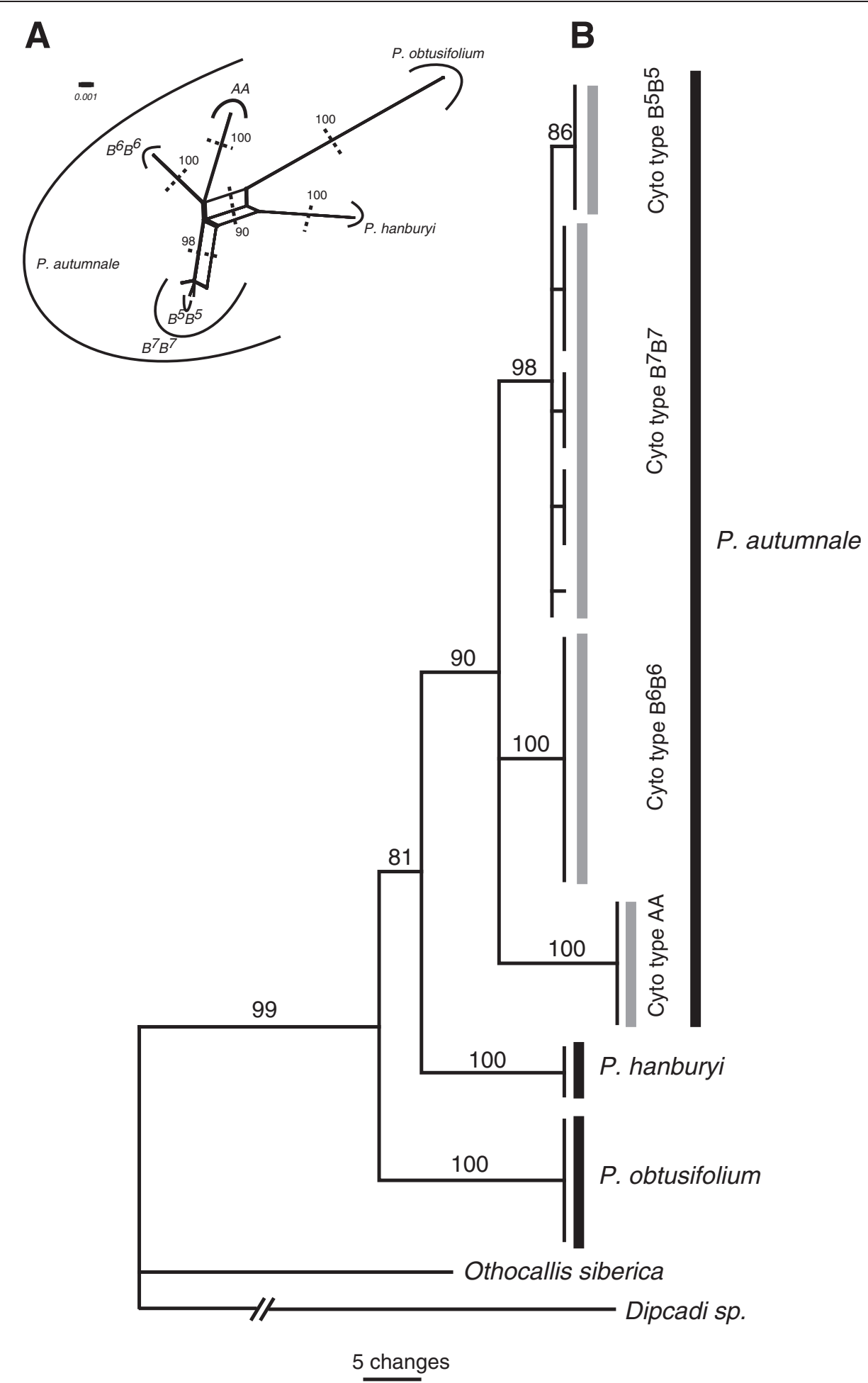

Figure 4 Phylogenetic relationships within the genus Prospero inferred from ITS sequence data. (A) NeighbourNet; (B) maximum parsimony phylogram. 


\section{Evolution of 5S and 35S rDNA loci}

$5 \mathrm{~S}$ and $35 \mathrm{~S}$ rDNA have been mapped to the chromosomes of all diploid species and cytotypes of the genus Prospero. This has allowed us to identify two and sometimes three chromosome pairs unambiguously (Figure 2). Thus, despite the high frequency of chromosomal rearrangements within and between populations of the P. autumnale complex - inversions, supernumerary segments, translocations, B-chromosomes [24,25,37,42] - all diploid cytotypes possess unique and stable locations of their rDNA loci (except for two $B^{6} B^{6}$ plants in this study with translocations). By contrast $5 \mathrm{~S}$ rDNA proved to be more variable in locus number and location (Figure 2), a phenomenon observed in other plant groups $[5,15,16,43,44]$. Despite this variability, $5 \mathrm{~S}$ rDNA is frequently more stable in its position than $35 \mathrm{~S}$ rDNA, which may vary substantially in distribution between related species (e.g., in Aloe [45]) and even between cells in individuals of species of genus Allium [46].

P. obtusifolium exhibits a remarkable pattern of rDNA distribution, unique within Prospero: juxtaposition of a centromere and the $35 \mathrm{~S}$ rDNA locus, with a 5S rDNA locus on each side (Figure 2A). Co-location of $35 \mathrm{~S}$ and 5S rDNA within the same chromosome or chromosomal arm has, however, been reported in other plant groups [16,47-49], sometimes even as 5S rDNA units inserted within $35 \mathrm{~S}$ rDNA repeats [17].

Within Hyacinthaceae, genera related to Prospero possess basic numbers of $x=7$ or higher [28]. Prospero obtusifolium forms the basal clade in the ITS-derived phylogeny. It probably represents an old segregate within the genus, which is estimated to be $6.43 \mathrm{Ma}$ old [40], and has experienced chromosomal rearrangements leading to a drastic chromosome number reduction to $x=4$.

$P$. hanburyi is the only species in the genus to possess a subterminally localized $35 \mathrm{~S}$ rDNA locus, instead of interstitial secondary constrictions adjacent to centromeres. It has been argued that a subterminal position for $35 \mathrm{~S}$ rDNA is ancestral [50], but in Prospero it might also be associated with a high potential of $35 \mathrm{~S}$ rDNA for generating chromosomal translocations [51,52]. The single $5 \mathrm{~S}$ rDNA locus is located in unique chromosomal position close to the centromere of chromosome 1 . It shares a common ancestry with the 5S rDNA locus of chromosome 1 in $P$. autumnale, as indicated by the phylogenetic analyses of the non-transcribed spacer region (K. Emadzade, H. Weiss-Schneeweiss et al., unpublished observations).

In contrast to the other two species, the diploids of the $P$. autumnale complex lend themselves to comparative karyotype analysis, due to the well-preserved chromosomal homoeology during evolution. Homoeology was first demonstrated in $\mathrm{A}$ and $\mathrm{B}^{7}$ diploid homoploid hybrids $[35,36]$, and was extended to $B^{7}, B^{6}$ and $B^{5}$ by analyses of meiotic pairing in diploid hybrids ([26,34], discussed below). The position of 35S rDNA is relatively conserved in the complex: within the long arm of chromosome 3, except when affected by the fusion in cytotype $\mathrm{B}^{5} \mathrm{~B}^{5}$. The NOR chromosome (3) in the $\mathrm{B}^{6}$ genome has a similar size and arm ratio to chromosome 3 in $\mathrm{B}^{7}$, but it differs in the proximity of the NOR to the centromere, probably as a result of paracentric inversion ("NOR shift", [24]). This regularity of interstitial position of 35S rDNA supports the earlier hypothesis [51] that it might provide greater karyomorphological stability during race or species evolution. The 5S rDNA loci are either interstitial in the distal part of the long arm of submetacentric chromosome 1 and/or proximal in the short arm of submetacentric chromosome 2, except where fusion has occurred in cytotype $\mathrm{B}^{5} \mathrm{~B}^{5}$ (Figures 2 and 3). The only variation observed in the complex was a putative duplication of $5 \mathrm{~S}$ rDNA locus in some copies of chromosome 1 of $\mathrm{B}^{7} \mathrm{~B}^{7}$. Although phylogenetic analyses of ITS sequences did not ascribe any evolutionary significance to this duplication, phylogenetic analyses of the more variable $5 \mathrm{~S}$ rDNA spacer (K. Emadzade, H. Weiss-Schneeweiss et al., unpublished observations) indicated that individuals carrying this duplication are more closely related to each other than to individuals carrying a single copy of the locus.

In addition to the between-cytotype variation in the number and distribution of $5 \mathrm{~S}$ rDNA loci, variation in FISH signal intensity has frequently been observed (e.g., in the $B^{6} B^{6}$ cytotype; Figure $\left.2 G\right)$. Signal strength differences are likely to be correlated with copy-number variation at the target site [53].

\section{Phylogenetic interpretation of chromosomal variation in Prospero}

The phylogeny of Prospero, inferred from ITS sequences, strongly supports monophyly of each species and diploid cytotype. P. obtusifolium and P. hanburyi are always recovered as subsequent sister groups to the $P$. autumnale complex. Neither species, however, has obvious chromosome homoeology with $P$. autumnale. By contrast, the ITS phylogeny coupled with knowledge of chromosome numbers, karyotype structure, and genome size allows us to test previous hypotheses concerning the direction and mechanisms of karyotype evolution within the $P$. autumnale complex (Figure 3, Additional file 1: Figure S1).

We offer a modified and more detailed model of the chromosomal changes involved in the origin of the cytotypes (Figure 3). Each cytotype forms a well-supported clade, with cytotype AA being the most distinctive. Cytotype AA is found only in the western distribution area of the genus, adjacent to the Atlantic Ocean and might have been isolated by a Pleistocene glacial advance.

The ITS phylogeny supports the origin of cytotype $B^{5} B^{5}$ from $B^{7} B^{7}$ rather than from $B^{6} B^{6}$, with genome $B^{6}$ being sister to $\mathrm{B}^{7}$. The close relationship of the localized 
cytotype $B^{5} B^{5}$ within the widespread cytotype $B^{7} B^{7}$ (Figure 4A) suggests its recent origin, and that it is the youngest segregate of the complex. Intra-cytotype ITS sequence variation has only been observed within the widespread cytotype $\mathrm{B}^{7} \mathrm{~B}^{7}$. This contrasts with a lack of variation in all other more geographically localized or endemic cytotypes and species. Thus phylogenetic and chromosomal data, and particularly the distribution of $5 \mathrm{~S}$ rDNA loci in cytotypes $\mathrm{B}^{5} \mathrm{~B}^{5}, \mathrm{~B}^{6} \mathrm{~B}^{6}$, and $\mathrm{B}^{7} \mathrm{~B}^{7}$, suggest independent and not sequential dysploidy: from $x=7$ to $x=6$ and independently from $x=7$ to $x=5$.

Model of karyotype evolution in Prospero autumnale complex Genome size estimations presented in the current study (Table 2, Figure 3) differ from genome size measurements published previously (Additional file 1: Figure S1) [26]. These previous measurements have been performed using Feulgen densitometry which could account, at least partially, for the discrepancy. However, Prospero genome size measurements reported in another study [37] are largely congruent with our data.

The chromosome number and structure of the Prospero ancestral karyotype (genus-wide) remains obscure, as do the karyotype relationships of the three species (K. Emadzade, T.-S. Jang, H. Weiss-Schneeweiss et al., unpublished observations). The ancestral chromosome number of the Prospero autumnale complex has been inferred as $x=7$, and this is also supported by phylogenetic reconstructions using extended plastid, ITS, and 5S rDNA spacer sequence datasets (K. Emadzade, H. WeissSchneeweiss et al., unpublished observations), with the ancestral karyotype similar in overall morphology to the A and $B^{7}$ genomes [24,34] (Figure 3). These genomes each possess one $5 \mathrm{~S}$ rDNA locus either in long arm of chromosome $1\left(5 \mathrm{~S}^{1} ; \mathrm{B}^{7}\right)$ or in the short arm of chromosome 2 $\left(5 \mathrm{~S}^{2} ; \mathrm{A}\right)$. Sequencing of the NTS regions of these loci shows them to be distinct (data not shown). We propose that the ancestral genome had both of these loci. The ancestral genome could have resembled $\mathrm{A}$ or $\mathrm{B}^{7}$ in size, or indeed be different from both, but increase is thought to be predominant to, and more rapid than, genome decrease. So resemblance of $\mathrm{B}^{7}$ to the ancestral karyotype is likely to be the most parsimonious, and genome increase might have occurred in the western refugium during a glacial maximum ([26], J. Parker, unpublished observations).

Loss of $5 \mathrm{~S}$ rDNA from chromosome $1\left(5 \mathrm{~S}^{1}\right)$ of the ancestral karyotype has likely accompanied evolution of cytotype AA. Its evolution has also been accompanied by nearly $70 \%$ genome size increase (Figure 3 ). Loss of the $5 \mathrm{~S}^{2}$ rDNA locus from the ancestral karyotype would give rise to cytotype $B^{7} B^{7}$ (Figure 3 ), now widespread across the whole Mediterranean basin. Interestingly, seven of the seventeen $\mathrm{B}^{7}$ diploids analysed carried a duplication of the $5 \mathrm{~S}^{1} \mathrm{rDNA}$ locus.
Genome $\mathrm{B}^{6}$ may have originated from the ancestral karyotype with $x=7$ by fusion of chromosomes 6 and 7 (Figure 3). It is also necessary to postulate a pericentric inversion and loss of a centromere in its evolution [26]. Previously, it had been proposed that the $\mathrm{B}^{6}$ genome evolved by chromosome fusion directly from $\mathrm{B}^{7}$ (Additional file 1: Figure S1). Evidence for the direct evolution from an ancestral karyotype rather than directly from $B^{7}$ comes from the retention of both the $5 \mathrm{~S}$ rDNA loci by $\mathrm{B}^{6}$. The analysis of meiotic pairing in hybrids does not differentiate between the two hypotheses $[24,26]$. The genome of $\mathrm{B}^{6}$ is $44 \%$ larger than $\mathrm{B}^{7}$, and the difference affects all chromosomes of the complement nearly equally. This is observed as bivalent asymmetry during meiosis in hybrids.

It was also proposed that $\mathrm{B}^{5}$ arose directly from $\mathrm{B}^{6}$ by a second fusion event [24]. The evidence came from the gross similarity of the largest fusion chromosomes in genomes $\mathrm{B}^{6}$ and $\mathrm{B}^{7}$ (thus they proposed $\mathrm{F}^{1}=\mathrm{F}^{2}$ ), and the presence of two trivalents at meiosis in $\mathrm{B}^{5} \mathrm{~B}^{7}$ hybrids. However, the molecular evidence presented here is consistent with $\mathrm{B}^{5}$ arising from $\mathrm{B}^{7}$, but supports evolution of $\mathrm{B}^{6}$ directly from an ancestral species of $P$. autumnale. The fusion chromosomes in $\mathrm{B}^{5}\left[\mathrm{~F}^{2}(1-6 / 7), \mathrm{F}^{3}(3-6 / 7)\right]$ and $\mathrm{B}^{6}$ $\left[\mathrm{F}^{1}(6-7)\right]$, therefore, have independent origins. No molecular markers are yet available to unequivocally identify chromosome 6 and 7, so the relationships of the fusion chromosomes cannot be explored more closely. The fusion chromosome $\mathrm{F}^{2}$ in cytotype $\mathrm{B}^{5}$ involving chromosome 1 and chromosome 6 or 7 [earlier proposed to be = to $F^{1}(6-7)$ ], gives rise to a near-metacentric, the largest in the complement. As expected, this carries a $5 \mathrm{~S}$ rDNA locus, which has been confirmed as $5 \mathrm{~S}^{1}$ by sequencing (K. Emadzade, H. Weiss-Schneeweiss et al., unpublished observations). In addition, the genome size of $\mathrm{B}^{5}$ is $12 \%$ higher than $\mathrm{B}^{7}$ but it cannot be established at what point this may have occurred. The cytotype $\mathrm{B}^{5} \mathrm{~B}^{5}$ is probably the most recently evolved diploid in the complex and is endemic to Libya, where it is the only race [34].

\section{Conclusions}

Phylogenetic analysis has confirmed fusion and basic number reduction as opposed to fission and basic number increase as the evolutionary mechanisms characterizing karyotype evolution in the $P$. autumnale complex. Dysploidy has occurred twice via independent fusions, once perhaps ancestral from $x=7$ to $x=6$, and later a second time from $x=7$ to $x=5$. This extensive chromosomal evolution contrasts very strongly with a lack of morphological diagnostic features within the genus, which are particularly weak within the $P$. autumnale complex [29,33,54]. New species described in last few decades usually refer to small populations that differ mostly in quantitative characters, whose evolutionary 
significance needs to be evaluated using a more thorough sampling. Diversification and evolution of this genus, then, has occurred primarily through genome restructuring, with little involvement of morphological change. Genetic processes may, of course, be implicated in the generation of chromosomal change. Thus, the genus Prospero, and in particular the $P$. autumnale complex, provides a model system for studying the role of chromosomes in plant diversification.

This study of diploids in Prospero has laid foundations (1) to address the evolution of auto- and allopolyploidy within the complex which appear to follow different evolutionary trajectories; $([26,42], H$. Weiss-Schneeweiss et al., unpublished observations), (2) to interpret the mechanisms involved in the origin and persistence of the many other types of chromosomal rearrangements that are found abundantly across the complex (such as Bchromosomes of many types, supernumerary segments on several chromosomes, translocations, and para- and pericentric inversions), and (3) to investigate the patterns of evolution of repetitive DNAs within the genus.

\section{Methods}

Plant material

Bulbs of all three Prospero species were collected from natural populations across the range (Table 1, Figure 1) and grown in the Botanical Garden of the University of Vienna. Due to high level of chromosomal variation, all individual bulbs were karyotyped prior to the FISH and phylogenetic analyses to select diploids (603 bulbs in total; T.-S. Jang, H. Weiss-Schneeweiss, unpublished observations). Where possible at least five bulbs with a "standard" (most common, without structural polymorphisms) karyotype were selected for the analyses; only three individuals with healthy root tips were available in P. hanburyi. Othocallis siberica and Dipcadi sp. (both in family Hyacinthaceae) were used as outgroup in phylogenetic analyses.

\section{Karyotype analysis and fluorescence in situ hybridization (FISH)}

Actively growing root-tip meristems were pretreated with $0.05 \%$ aqueous solution of colchicine for $4 \mathrm{~h}$ at room temperature, fixed in ethanol : acetic acid $(3: 1)$ for at least $3 \mathrm{~h}$ at room temperature, and stored at $-20^{\circ} \mathrm{C}$ until use.

Chromosome counting and basic karyotype analyses were performed using the standard Feulgen staining technique [55]. Ideograms (Additional file 2: Figure S2) were constructed based on measurements of at least five wellspread metaphase plates per individual (not shown) and measurements were used to calculate Haploid Karyotype Length (HKL). A single ideogram of each species and cytotype is provided, except for cytotypes $B^{7} B^{7}$ and $B^{6} B^{6}$ in which structural chromosomal variants were found (Table 2). Idiograms were constructed using Autoidiogram software (courtesy of Dr Wolfgang Harand, formerly University of Vienna; for details see [55]).

Chromosomal spreads for FISH were prepared by enzymatic digestion and squashing, as described earlier $[4,16]$ with some modifications. Briefly, material was digested with 1\% cellulase Onozuka (Serva, Heidelberg, Germany), 1\% cytohelicase (Sigma-Aldrich, Vienna, Austria), and $1 \%$ pectolyase (Sigma-Aldrich) for $18 \mathrm{~min}$ at $37^{\circ} \mathrm{C}$. Cover slips were removed at $-80^{\circ} \mathrm{C}$ and preparations air-dried. FISH followed the established protocol $[16,56]$. Probes used for FISH were: 35S (18S/25S) rDNA from Arabidopsis thaliana in plasmid pSK+; $5 \mathrm{~S}$ rRNA genic region from Melampodium montanum in plasmid pGEM-T Easy. Probes were labeled with biotin or digoxygenin (Roche, Vienna, Austria) either directly by PCR (5S rDNA) or using a nick translation kit (35S rDNA; Roche, Vienna, Austria). Digoxygenin was detected with antidigoxygenin antibody conjugated with FITC $\left(5 \mu \mathrm{g} \mathrm{mL}{ }^{-1}\right.$ : Roche, Vienna, Austria) and biotin with ExtrAvidin conjugated with Cy3 (2 $\mu \mathrm{g} \mathrm{mL} \mathrm{mL}^{-1}$ : Sigma-Aldrich, Vienna, Austria). Preparations were analyzed with an AxioImager M2 epifluorescent microscope (Carl Zeiss, Vienna, Austria), images captured with a CCD camera, and processed using AxioVision ver. 4.8 (Carl Zeiss, Vienna, Austria) with only those functions that apply equally to the whole image. For rDNA localization, a minimum of 20 well-spread metaphases and prometaphases was analysed for each individual.

\section{DNA amplification, sequencing, and phylogenetic approach}

Total genomic DNA was extracted from silica-dried leaf material using the standard CTAB procedure [57] with some modifications [58]. The nuclear ITS region (partial $18 \mathrm{~S}$ rRNA gene, ITS1, 5.8S rRNA gene, ITS2, and partial $25 \mathrm{~S}$ rRNA gene) was amplified with universal primers (ITS 18 s F and ITS 26 s R, [59]).

Polymerase chain reactions were carried out using $0.4 \mathrm{mM}$ of each primer, ReddyMix (Abgene, Vienna, Austria) including $2.5 \mathrm{mM} \mathrm{MgCl}_{2}$ and $4 \%$ (v/v) dimethyl sulfoxide (DMSO). All PCR reactions were performed on an ABI thermal cycler 9700 (Applied Biosystems, Foster City, CA, USA) with the initial $3 \mathrm{~min}$ at $95^{\circ} \mathrm{C}$, followed by 30 cycles each of $30 \mathrm{~s}$ at $96^{\circ} \mathrm{C}, 30 \mathrm{~s}$ at $58^{\circ} \mathrm{C}$, and $2 \mathrm{~min}$ at $72^{\circ} \mathrm{C}$, followed by a final elongation at $72^{\circ} \mathrm{C}$ for $8 \mathrm{~min}$. Amplified fragments were checked on 1\% (w/v) agarose gel and purified using exonuclease I (ExoI) and calf intestine alkaline phosphatase (CIAP) according to the manufacturer's protocol (Fermentas, St. Leon-Rot, Germany). The purified fragments were directly sequenced using the PCR primers and dye terminator chemistry following the manufacturer's protocol (Applied Biosystems). Sequencing 
reactions were run on a 48-capillary sequencer (3730 DNA Analyzer, Life Technologies). Sequences were assembled in SeqManII (Lasergene, Madison, WI) and manually aligned in BioEdit software ver. 7.0.5.3 [60]. Indels were coded as binary characters following the "modified complex coding method" [61] using the program SeqState version 1.36 [62], and the dataset with coded gaps was used for all analyses. A heuristic search for most parsimonious (MP) trees was performed using PAUP 4.0.b10 [63]. The analyses involved 1000 replicates of random sequence addition, with tree bisection-reconnection (TBR) and branch swapping, saving no more than 10 trees per replicate. All characters were equally weighted and treated as unordered. Strict consensus trees were computed from all equally most parsimonious trees. Internal branch support was estimated using nonparametric bootstrapping [64] with 10000 replicates and 10 addition sequences replicates. Neighbor Net implemented in SplitsTree4 v. 4.11 .3 [65], with gaps and ambiguous sites treated as missing data, was used to create the ITS network. Split support was calculated with 1000 bootstrap replicates. All ITS sequences are deposited in GenBank (accession numbers provided in Table 1) and the alignment and phylogeny are deposited in treeBASE (submission number 14243).

\section{Genome size estimation by flow cytometry (FCM)}

The $1 C$ values of all Prospero species and each cytotype of $P$. autumnale complex were measured using FCM with Solanum pseudocapsicum $(1 C=1.29 \mathrm{pg}$, [66]) as the internal standard. Approximately $25 \mathrm{mg}$ fresh leaves from each plant sample were co-chopped together [67] with standard material in Otto's buffer I [68], and filtered through a $30 \mu \mathrm{m}$ Nylon mesh. After $30 \mathrm{~min}$ RNase treatment at $37^{\circ} \mathrm{C}$, the nuclei were stained in Otto's buffer II [68] containing propidium iodide as the DNA stain. A CyFlow ML flow cytometer equipped with green laser (100 mW, $532 \mathrm{~nm}$; Cobolt Samba; Cobolt AB, Stockholm, Sweden) was used for genome size estimation. The $1 C$ values were calculated according to previously published formula [66].

\section{Availability of supporting data}

Nucleotide sequences are available in GenBank (http:// www.ncbi.nlm.nih.gov/genbank) under numbers KC899267KC899317. Nucleotide alignment and phylogenetic analyses are deposited in treeBASE under study 14243 (http:// purl.org/phylo/treebase/phylows/study/TB2:S14243).

\section{Additional files}

Additional file 1: Figure S1. Previous hypothesis on karyotype evolution in the Prospero autumnale complex [26]. Black arrows indicate more parsimonious hypotheses, empty arrows indicate alternatives.
Additional file 2: Figure S2. Ideograms of each of the standard (most frequent and without polymorphisms) diploid species and cytotypes analysed.

Additional file 3: Figure S3. Alignment of variable nucleotide positions in the analysed ITS region.

\section{Competing interests}

The authors declare that they have no competing interests.

\section{Authors' contributions}

TS-J carried out the cytogenetic studies, participated in the sequence alignment and drafted the manuscript. KE carried out sequencing of the ITS regions, sequence alignments, and phylogenetic analyses, and helped to draft the manuscript. JP provided plant material, participated in the design of the study and data interpretation, and helped to draft the manuscript. EMT carried out genome size measurements. ARL participated in the design of the study and data interpretation, and helped to draft the manuscript. FS provided plant material and helped to draft the manuscript. HW-S conceived of the study, and participated in its design and coordination and helped to draft the manuscript. All authors read and approved the final manuscript.

\section{Acknowledgements}

The authors acknowledge financial support of the Austrian Science Fund (FWF) project P21440-B03 to HWS.

\section{Author details}

'Department of Systematic and Evolutionary Botany, University of Vienna, Rennweg 14, A-1030, Vienna, Austria. ${ }^{2}$ Cambridge University Botanic Garden, Cambridge CB2 1JF, UK. ${ }^{3}$ Queen Mary College, University of London, London, UK. ${ }^{4}$ Dornacher Strasse 1, Linz 4040, Austria.

Received: 3 April 2013 Accepted: 27 June 2013

Published: 3 July 2013

\section{References}

1. Lysak MA, Berr A, Pecinka A, Schmidt R, McBreen K, Schubert I: Mechanisms of chromosome number reduction in Arabidopsis thaliana and related Brassicaceae species. Proc Natl Acad Sci USA 2006, 103:5224-5229.

2. Schubert I: Chromosome evolution. Curr Opin Plant Biol 2007, 10:109-115.

3. Clarkson JJ, Lim KY, Kovarik A, Chase MW, Knapp S, Leitch AR: Long-term genome diploidization in allopolyploid Nicotiana section Repandae (Solanaceae). New Phytol 2005, 168:241-252.

4. Weiss-Schneeweiss H, Tremetsberger K, Schneeweiss GM, Parker JS, Stuessy TF: Karyotype diversification and evolution in diploid and polyploidy South American Hypochaeris (Asteraceae) inferred from rDNA localization and genetic fingerprint data. Ann Bot 2008, 101:909-918.

5. Weiss-Schneeweiss H, Schneeweiss GM: Karyotype diversity and evolutionary trends in angiosperms. In Plant Genome Diversity. Volume 2. Physical Structure, Behavior and Evolution of Plant Genomes. Edited by Leitch IJ, Greilhuber J, Doležel J, Wendel JF. Springer-Verlag: Wien; 2013:209-230.

6. Kulikova O, Gualtieri G, Geurts R, Kim DJ, Cook D, Huquet T, De Jong JH, Fransz PF, Bisseling T: Integration of the FISH pachytene and genetic maps of Medicago truncatula. Plant J 2001, 27:49-58.

7. Cuadrado A, Jouve N: Evolutionary trends of different repetitive DNA sequences during speciation in the genus Secale. J Hered 2002, 93:339-345.

8. Mishima M, Ohmido N, Fukui K, Yahara T: Trends in site-number change of rDNA loci during polyploidy evolution in Sanguisorba (Rosaceae). Chromosoma 2002, 110:550-558.

9. Pedrosa A, Sandal N, Stougaard J, Schweizer D, Bachmair A: Chromosomal map of the model legume Lotus japonicus. Genetics 2002, 161:1661-1672.

10. Schwarzacher T, Heslop-Harrison P: Practical in situ Hybridization. 2nd edition. Oxford, UK: BIOS; 2000.

11. Lim KY, Matyasek R, Lichtenstein CP, Leitch AR: Molecular cytogenetic analyses and phylogenetic studies in the Nicotiana section Tomentosae. Chromosoma 2000, 109:245-258.

12. Schmidt T, Heslop-Harrison JS: High-resolution mapping of repetitive DNA by in situ hybridization: molecular and chromosomal features of prominent dispersed and discretely localized DNA families from the wild beet species Beta procumbens. Plant Mol Biol 1996, 30:1099-1113. 
13. Mandakova T, Mummenhoff K, Al-Shehbaz IA, Mucina L, Mühlhausen A, Lysak MA: Whole-genome triplication and species radiation in the southern African tribe Heliophileae (Brassicaceae). Taxon 2012, 61:989-1000.

14. Weiss-Schneeweiss H, Schneeweiss GM, Stuessy TF, Mbuchi T, Park JM, Jang CG, Sun BY: Chromosomal stasis in diploids contrasts with genome restructuring in auto- and allopolyploid taxa of Hepatica (Ranunculaceae). New Phytol 2007, 174:669-682

15. Mlinarec J, Šatović Z, Malenica N, Ivančić-Baće I I, Besendorfer V: Evolution of the tetraploid Anemone multifida $(2 n=32)$ and hexaploid $A$. baldensis $(2 n=48)$ (Ranunculaceae) was accompanied by rDNA loci loss and intergenomic translocation: evidence for their common genome origin. Ann Bot 2012, 110:703-712.

16. Weiss-Schneeweiss H, Blöch C, Turner B, Villaseñor JL, Stuessy TF, Schneeweiss GM: The promiscuous and the chaste: frequent allopolyploid speciation and its genomic consequences in American daisies (Melampodium sect. Melampodium, Asteraceae). Evolution 2012, 66:211-228

17. Garcia S, Panero JL, Siroky J, Kovarik A: Repeated reunions and splits feature the highly dynamic evolution of $5 \mathrm{~S}$ and $35 \mathrm{~S}$ ribosomal RNA genes (rDNA) in the Asteraceae family. BMC Plant Biol 2010, 10:176.

18. Lapitan NLV, Ganal MW, Tanksley SD: Organization of the 5 S ribosomal RNA genes in the genome of tomato. Genome 1991, 34:509-514.

19. Sastri DC, Hilu K, Appels R, Lagudah ES, Playford J, Baum BR: An overview of evolution in plant 5S DNA. Plant Syst Evol 1992, 183:169-181.

20. Maluszynska J, Hasterok R, Weiss H: rRNA genes - Their distribution and activity in plants. In Plant cytogenetics. Edited by Maluszynska J. Katowice: Silesian University Press; 1998.

21. Heslop-Harrison JS: Comparative genome organization in plants: from sequence and markers to chromatin and chromosomes. Plant Cell 2000, 12:617-636

22. Krishnan P, Sapra VT, Soliman KM, Zipf A: FISH mapping of the 5 S and 18S28S rDNA loci in different species of glycine. J Hered 2001, 92:282-287.

23. Zimmer EA, Wen J: Using nuclear gene data for plant phylogenetics: progress and prospects. Mol Phylogenet Evol 2012, 65:774-785.

24. Ainsworth CC, Parker JS, Horton DM: Chromosome variation and evolution in Scilla autumnalis. In Kew Chromosome Conference II. Edited by Brandham PE, Bennett MD. London: George Allen \& Unwin; 1983:261-268.

25. Parker JS, Lozano R, Taylor S, Ruiz Rejòn M: Chromosomal structure of populations of Scilla autumnalis in the Iberian Peninsula. Heredity 1991, 67:287-297.

26. Vaughan HE, Taylor S, Parker JS: The ten cytological races of the Scilla autumnalis species complex. Heredity 1997, 79:371-379.

27. Speta F: Die Gattungen Scilla L. s. str. und Prospero Salisb. im pannonischen Raum. Veröffentl Intern Clusius-Forschungsges Güssing 1982, 5:1-19.

28. Speta F: Systematische Analyse der Gattung Scilla L. s.l. (Hyacinthaceae). Phyton 1998, 38:1-141.

29. Speta F: Beitrag zur Kenntnis der Gattung Prospero Salisb (Hyacinthaceae) auf der griechischen Insel Kreta. Linz Biol Beitr 2000, 32:1323-1326.

30. Tzanoudakis D, Kypriotakis Z: A new polyploid Scilla (Liliaceae) from the Cretan area (Greece). Folia Geobot 1998, 33:103-108.

31. Jeanmonod D, Gamisans J: Flora Corsica. Edisud: Aix-en-Provence La Compagnie des éditions de la Lesse; 2007

32. Brullo C, Brullo S, Gtusso Del Galdo G, Pavone P, Salmeri C: Prospero hierae (Hyacinthaceae), a new species from Marettimo Island (Sicily). Phyton 2009, 49:93-104.

33. Govaerts R, Zonneveld BJM, Zona SA: World Checklist of Asparagaceae, Facilitated by the Royal Botanic Gardens Kew. UK. http://apps.kew.org/wcsp/ Retrieved 2013-03-18.

34. Taylor S: Chromosomal evolution of Scilla autumnalis, PhD thesis. London, UK: University of London; 1997.

35. White J, Jenkins G, Parker JS: Elimination of multivalents during meiotic prophase in Scilla autumnalis. I. Diploid and triploid. Genome 1988, 30:930-939.

36. Jenkins $G$, White J, Parker JS: Elimination of multivalent during meiotic prophase in Scilla autumnalis II. Tetraploid. Genome 1988, 30:940-946.

37. Ebert I, Greilhuber J, Speta F: Chromosome banding and genome size differentiation in Prospero (Hyacinthaceae): diploids. Plant Syst Evol 1996, 203:143-177.

38. Pfosser M, Speta F: Phylogenetics of Hyacinthaceae based on plastid DNA sequences. Ann Mo Bot Gard 1999, 86:852-875.
39. Pfosser M, Wetschnig W, Ungar S, Prenner G: Phylogenetic relationships among genera of Massonieae (Hyacinthaceae) inferred from plastid DNA and seed morphology. J Plant Res 2003, 116:115-132.

40. Ali SS, Yu Y, Pfosser M, Wetschnig W: Inferences of biogeographical histories within subfamily Hyacinthoideae using S-DIVA and Bayesian binary MCMC analysis implemented in RASP (Reconstruct Ancestral State in Phylogenies). Ann Bot 2012, 109:95-107.

41. Hong DY: Cytotype variation and polyploidy in Scilla autumnalis L. (Liliaceae). Hereditas 1982, 97:227-235.

42. Vaughan HE, Jamilena M, Ruiz Rejón C, Parker JS, Garrido-Ramos MA: Loss of nucleolar-organizer regions during polyploidy evolution in Scilla autumnalis. Heredity 1993, 71:574-580.

43. Hasterok R, Wolny E, Hosiawa M, Kowalczyk M, Kulak-Ksiazczyk S, Ksiazczyk T, Heneen WK, Maluszynska J: Comparative analysis of rDNA distribution in chromosomes of various species of Brassicaceae. Ann Bot 2006, 97:205-216.

44. Fukushima K, Imamura K, Nagano K, Hoshi Y: Contrasting patterns of the $5 \mathrm{~S}$ and $45 \mathrm{~S}$ rDNA evolutions in the Byblis liniflora complex (Byblidaceae). J Plant Res 2011, 124:231-244.

45. Adams SP, Leitch IJ, Bennett MD, Chase MW, Leitch AR: Ribosomal DNA evolution and phylogeny in Aloe (Asphodelaceae). Am J Bot 2000, 87:1578-1583.

46. Schubert I, Wobus U: In situ hybridization confirms jumping nucleolus organizing regions in Allium. Chromosoma 1985, 92:143-148.

47. Ali HB, Fransz P, Schubert I: Localization of 5S RNA genes on tobacco chromosomes. Chromosome Res 2000, 8:85-87.

48. Siroky J, Lysak MA, Doležel J, Kejnovsky E, Vyskot B: Heterogeneity of rDNA distribution and genome size in Silene spp. Chromosome Res 2001, 9:387-393.

49. Pires JC, Lim KY, Kovarik A, Matyasek R, Boyd A, Leitch AR, Leitch IJ, Bennett $M D$, Soltis PS, Soltis DE: Molecular cytogenetic analysis of recently evolved Tragopogon (Asteraceae) allopolyploids reveal a karyotype that is additive of the diploid progenitors. Am J Bot 2004, 91:1022-1035.

50. Roa F, Guerra M: Trends on the distribution of the 45S rDNA ribosomal DNA in plants. In Abstract book of Annual Main Meeting of the Society for Experimental Biology: 30 June-3 July. Prague. London: Society for Experimental Biology; 2010:262.

51. Hanson RE, Islam-Faridi MN, Percival EA, Crane CF, Ji Y, McKnight TD, Stelly DM, Price HJ: Distribution of 5S and 18-28S rDNA loci in a tetraploid cotton (Gossypium hirsutum L.) and its putative diploid ancestors. Chromosoma 1996, 105:55-61.

52. Pedrosa-Harand A, De Almeida CC S, Mosiolek M, Blair MW, Schweizer D, Guerra M: Extensive ribosomal DNA amplification during Andean common bean (Phaseolus vulgaris L.) evolution. Theor Appl Genet 2006, 112:924-933.

53. Leitch IJ, Heslop-Harrison JS: Physical mapping of the 18S-5.8S-26S rRNA genes in barley by in situ hybridization. Genome 1992, 35:1013-1018.

54. Hamouche Y, Amirouche N, Misset MT, Amirouche R: Cytotaxonomy of autumnal flowering species of Hyacinthaceae from Algeria. Plant Syst Evol 2010, 285:177-187.

55. Weiss-Schneeweiss H, Villaseñor JL, Stuessy TF: Chromosome numbers, karyotypes, and evolution in Melampodium (Asteraceae). Int J Plant Sci 2009, 170:1168-1182.

56. Weiss-Schneeweiss H, Riha K, Jang CG, Puizina J, Scherthan H, Schweizer D: Chromosome termini of the monocot plant Othocallis siberica are maintained by telomerase, which specifically synthesises vertebrate-type telomere sequences. Plant J 2004, 37:484-493.

57. Doyle JJ, Doyle JL: A rapid DNA isolation procedure for small quantities of fresh leaf tissue. Phytochem Bull 1987, 19:11-15.

58. Tel-Zur N, Abbo S, Myslabodski D, Mizrahi Y: Modified CTAB procedure for DNA isolation from epiphytic cacti of the genera Hylocereus and Selenicereus (Cactaceae). Plant Mol Biol Rep 1999, 17:249-254.

59. Gruenstaeudl M, Urtubey E, Jansen RK, Samuel R, Barfuss MH, Stuessy TF: Phylogeny of Barnadesioideae (Asteraceae) inferred from DNA sequence data and morphology. Mol Phylogenet Evol 2009, 51:572-587.

60. Hall TA: BioEdit: a user-friendly biological sequence alignment editor and analysis program for Windows 95/98NT. Nucleic Acids Symp Ser 1999 41:95-98.

61. Simmons MP, Ochoterena H: Gaps as characters in sequence-based phylogenetic analyses. Syst Biol 2000, 49:369-381.

62. Müller K: SeqState-primer design and sequence statistics for phylogenetic DNA data sets. Appl Bioinformatics 2005, 4:65-69.

63. Swofford DL: PAUP*: phylogenetic analysis using parsimony (*and other methods). version 4.0.610. Sunderland, MA: Sinauer Associates; 2002. 
64. Felsenstein J: Confidence limits on phylogenies: An approach using the bootstrap. Evolution (N Y) 1985, 39:783-791.

65. Huson DH, Bryant D: Application of phylogenetic networks in evolutionary studies. Mol Biol Evol 2010, 23:254-267.

66. Temsch EM, Greilhuber J, Krisai R: Genome size in liverworts. Preslia 2010, 82:63-80.

67. Galbraith DW, Harkins KR, Maddox JM, Ayres NM, Sharma DP, Firoozabady E: Rapid flow cytometric analysis of the cell cycle in intact plant tissues. Science 1983, 220:1049-1051.

68. Otto F, Oldiges $H$, Gohde W, Jain VK: Flow cytometric measurement of nuclear DNA content variations as a potential in vivo mutagenicity test. Cytometry 1981, 2:189-191.

doi:10.1186/1471-2148-13-136

Cite this article as: Jang et al:: Chromosomal diversification and

karyotype evolution of diploids in the cytologically diverse genus Prospero (Hyacinthaceae). BMC Evolutionary Biology 2013 13:136.

\section{Submit your next manuscript to BioMed Central and take full advantage of:}

- Convenient online submission

- Thorough peer review

- No space constraints or color figure charges

- Immediate publication on acceptance

- Inclusion in PubMed, CAS, Scopus and Google Scholar

- Research which is freely available for redistribution 